J O U R A L O F

French and Francophone Philosophy
REVUE DE LA

philosophie française et de langue française

\title{
Beyond Dualism and Monism: Bergson's Slanted Being
}

Messay Kebede

Journal of French and Francophone Philosophy - Revue de la philosophie française et de langue française, Vol XXIV, No 2 (2016) 106-130.

\author{
Vol XXIV, No 2 (2016) \\ ISSN 1936-6280 (print) \\ ISSN 2155-1162 (online) \\ DOI $10.5195 /$ jffp. 2016.773 \\ www.jffp.org
}

\section{(c) EY-NC-ND}

This work is licensed under a Creative Commons Attribution-Noncommercial-No Derivative Works 3.0 United States License.

\section{ULIS D-Sunt}

This journal is operated by the University Library System of the University of Pittsburgh as part of its D-Scribe Digital Publishing Program, and is co-sponsored by the University of Pittsburgh Press 


\title{
Beyond Dualism and Monism
}

\section{Bergson's Slanted Being}

\author{
Messay Kebede \\ University of Dayton
}

There is an old but still unresolved debate pertaining to the "question of Bergsonian monism or dualism." 1 Scholars who believe that Henri Bergson is ultimately monist clash with those who argue that he has consistently maintained a dualist position. Others speak of contradiction, basing their allegation on what they regard as a failure to reconcile dualism with monism. What fuels the debate is Bergson's undeniable change of direction: while his first book is overtly dualist, his second book takes a sharp turn toward monism. Without denying the intricacy generated by the change of direction, I argue that the originality of Bergson's position is overlooked when the problem is presented in terms of him being dualist or monist. Notably, I contend that Bergson's third book, Creative Evolution, overcomes both dualism and monism by removing their contradiction through a durational approach to being. To support the contention, I engage in a series of confrontations with Gilles Deleuze's interpretation of Bergson, the Hegelian dialectics, and Nietzsche's doctrine of eternal recurrence.

\section{The Impasse of Monism and Dualism}

Given the drastically differing attributes of the world, a unified vision of reality has always been a great challenge to philosophers. From brute materiality through vital functions to spiritual manifestations, the world exhibits modes of being that elude integration. Attempts to unify the world on the basis of spirituality or materiality define the various monistic schools of idealism and materialism. Conversely, diverse schools of dualism expose the implausibility of the monist integration and propose an ontological separation between mind and matter. A less crowded third school of thought argues that integration becomes feasible when it operates on the basis of vitalism, where matter and mind are respectively lower and higher forms of vital activity. 
Whether monism is spiritualist or materialist, the main obstacle is the set of complex issues that arise from reductionism. If we take the case of Berkeley's immaterialism, despite his often pertinent challenges to dualism and materialism, he stumbles each time he has to account for the undeniable independence and law-governed nature of the perceived world. Granted that matter cannot be anything other than an idea, the fact that all the ideas of sense perception are independent of the will of the perceiving subject requires an explanation that cannot but seriously challenge the system. In effect, to account for the objective nature of our perceptions despite the elimination of materiality, Berkeley assumes that "some other Will or Spirit," namely God, "produces them." 2 Rather than a solution, this appeal to God only bestows a greater plausibility on the dualist opposition of mind and matter and the materialist unification of the world than on immaterialism.

No sooner is materialist monism credited with soundness than the weakness of its reductionism jumps out. Even though the theory owes its credibility to its presumed agreement with the trend of scientific advances, it cannot avoid implications that are philosophically difficult to defend. From the philosophical perspective, the reduction of spirit to a material phenomenon presupposes nothing other than the theory making the brain into an organ of representation. The theory that the brain secretes consciousness and thoughts like the liver produces bile rests on the assumption that materiality hides unknown virtues of the kind that defy and transfigure its known characteristics. The reduction becomes plausible only to the extent that we concede that matter is really something other than what it appears to be. This concession simply destroys the alleged strong point of materialism, namely, its ability to explain the world without appealing to occult attributes.

The dualist position does not present a better shape: while its insistence on the gap between materiality and the various functions of the mind constitutes its strength, the solution to separate ontologically matter and spirit runs into the knotty problem of the unity of mind and body. Thus, in assigning matter and thinking to two different and separate substances, Descartes faced the insuperable task of uniting what he drastically had separated. Though undeniable, the interaction between mind and body looks impossible once the mind is said to be "entirely different from the body." 3 How could that which is unextended act on the extended and, inversely, how could that which is given in space impact on what is not extended? Descartes's explanation that the pineal gland is where the contact between soul and body takes place does nothing to lessen the difficulty of the alleged interaction. Some of Descartes's most famous successors, namely Spinoza and Leibniz, completely drop the idea of contact in favor of a more consistent separation. Spinoza argues that the correspondence between the physical and the mental results from the oneness of the divine substance in which extension and thought are parallel attributes. Leibniz prefers the 
theory of pre-established harmony according to which God's active programming removes the need for a direct contact and explains the harmony between mind and body.

The difficulty to unite mind and body equally obscures the way objective knowledge is acquired. It is obvious with dualism: since matter and mind are totally different substances, what is known is just a subjective translation of the object, and never the object itself. Unsurprisingly, this line of thinking could lead nowhere but to Kantian relativism, to the idea that the mind uses its own tools to construct the object, with the consequence that the object in itself becomes unknowable. The need to counter relativism gave reductionism a powerful appeal. Given the Kantian premises, overcoming relativism could only mean the identification of the subjective and the objective by reducing the object either to a mental state, as do the various schools of German idealism, or the mental to the material, as advocated by materialism. Unfortunately, the reductionism of idealism always entails the negation of the autonomy of the object, while that of materialism invariably cancels subjectivity by scaling it down to a cerebral phenomenon. In both cases, it is the ontological distinction, so dear to Descartes, between subject and object that is rejected without an alternative theory able to satisfactorily explain the distinction in monistic terms.

The ultimate source of all these intractable problems lies in the dualist thinking opposing mind and body, which monism rejects by defending reductionism. Far from reducing the opposition of two distinct substances, Descartes's successors intensified it further by defending the parallel series of thought and extension or their preestablished harmony. In thus rejecting the idea of contact, not only do they widen the gap, but they also posit "an equivalence between the cerebral and the mental," which equivalence could not but appear as a useless duplication. ${ }^{4}$ What else could then follow but the idea of trading a useless duplication for a more consistent idealistic monism? Better still, the stronger the equivalence is supposed to be, the more probable becomes the perception of the mind as inessential to the great benefit of materialist epiphenomenalism, that is, to the belief that physical processes cause mental events.

\section{Breaking Through the Ontological Impasse}

The reality of a standoff indicates, as Arnaud François notes, that "classical dualism is not the opposite of monism." 5 It is because monist and dualist theories equally share the same belief that they are bound to clash in the vain attempt to overcome the initial deficiency of their common refusal to integrate dualism into the unity of being. As much as dualism opposes and separates spiritual and material substances, monism defends the oneness of being. As such, both equally abhor the idea of ontological mixture. Just as dualism refuses mixture, the attempt to reduce matter to spirit or vice versa 
reveals the same repugnance towards a composite reality. Being is either physical or mental; it cannot be both at the same time. It either can be physical by being distinct from the mental, or one of the two is reducible to the other.

The opposing method of dualism mistakenly considers only extremes by contrasting the rudimentary forms of matter with the highest functions of mind. The error of monism is to jump into reductionism when the sensible approach should be to narrow the gap between mind and matter. Accordingly, both monism and dualism must first abandon their tendency to "suppress all spontaneity and all initiative from matter."6 In characterizing matter as purely inert, mechanical, and lifeless, dualism and monism insert an insurmountable gap between mind and matter. As a result, dualism cannot account for their interaction, and monism cannot derive the mental from the inert or vice versa. By contrast, the attempt to narrow the gap opens up the possibility of transition from the one to the other. The consequence is that differentiation instead of opposition would define the relationship between the mental and the material. Since neither dualism nor monism succeeds in their respective attempts, we must drop the opposition of two substances, as well as the effort to reduce the one to the other. Instead, we must show how the subjective grows out and develops from the objective, not as duplication, but as differentiation from the original unity of being. In a word, we must speak in terms of genesis, of creation rather than duality or reductionability.

Differentiation introduces the notion of difference in nature or kind, which is distinct from the notion of difference in degree. The latter varies quantitatively the same; the former rises to heterogeneity, thereby generating a "difference between same and other."7 In addition to establishing origination from the same unity, differentiation in kind adds a qualitative denotation that prevents reductionism so that derivation from a single source does not signify sameness. Difference in kind also incorporates the attribute of novelty or creation that makes it irreducible to the original matrix. The right approach, Pierre Montebello says, is "to respect differences in nature, but without forgetting to account for the genetic passages that show their differentiation."8 Put otherwise, differences are real and absolute but also related as transitional moments. Everything is thus related while also being different. This approach both unifies and dissociates: there is continuity between matter, life, and spirit that results into qualitatively different modes of being.

This derivation of differences obviously makes room for an evolutionary approach that is essentially creative. Creation underlines a cardinal facet, namely, that while it is true to say that higher forms originate from lower ones, it is wrong to conclude that the former were somehow contained in the lower moments. Any suggestion of prior inclusion, either potentially or otherwise, would be a return to reductionism. Because the 
higher was not implicitly given, the mere quantitative modification of the lower is not enough to explain its generation. It requires a qualitative leap that can only be explained by the involvement of a creative act, given that only creation can account for the appearance of novelty. In this way, the essential concern of dualism is preserved without the entanglement of two alien substances. This unity of being effectively removes the major weakness of dualism in that the complete separation of the mind from materiality is but an invitation to view it as an epiphenomenon. Surely, the appearance of the mind in a world that completely ignores it can only instigate the materialist concept of epiphenomenality. According to Bergson, "the great error of the doctrines on the spirit has been the idea that by isolating the spiritual life from all the rest, by suspending it in space as high as possible above the earth, they were placing it beyond attack, as if they were not thereby simply exposing it to be taken as an effect of mirage!"9 Indeed, dualism thought that the sure way to guarantee the distinction of the mind from the body was to separate them in such a way that they belong to different substances. To the extent that this ontological separation provides no bridge between the two and that only the material possesses the virtue of being empirically observable, there is enough reason to conjecture that what is not empirically given is just an illusion, an appearance devoid of reality.

What forcefully emerges from the above discussion is the question of knowing what being must be for it to support indefinite qualitative differentiations. The question amounts to asking about real genesis as opposed to that which is simply unfolding what already exists. Dualism refuses to speak of a genesis of spirit from materiality; monism, too, since a genetic approach would challenge reductionism. And with real genesis, what else is asserted but the efficacy of time, the very one making "real duration" into a process "in which each form flows out of previous forms, while adding to them something new?"10 Let us see how duration, as understood by Bergson, overcomes the conflict between dualism and monism.

\section{Duration as the Stuff of Reality}

What distinguishes the Bergsonian conception is the attribution of real objectivity and dynamism to duration. A glimpse at the main representative theories, aside from the most common view of time as an entity by itself, shows conceptions of time ranging from representation, relation, to intentionality. We owe to Kant the clear conception of time as representation subsequent to his rejection of Leibniz's theory of time as the order of succession of things. According to Kant, space and time constitute two forms of intuition that the mind uses to perceive the coexistence and succession of things. This a priori, ideal nature of time means that things are perceived through time instead of being in time. Redirecting and amplifying the 
Kantian direction, phenomenology captures time as intentionality. More than just a subjective form, time is constitutive of the subject; it is the act by which consciousness becomes conscious of by distancing itself from itself and objects in the form of past, present, and future.

Bergson attracted the attention of the philosophic community by going against the dominant position, to wit, the confinement of time to subjectivity. His pre-critical stand does not reject the subjective version of time, as shown by the fact that Bergson distinguishes between homogenous or spatialized time and real, objective time or duration (la durée), the defining feature of the latter being interpenetration or non-juxtaposing continuity. The former is a category of action: it establishes the order of succession by separating past, present, and future. ${ }^{11}$ The latter is a process of creation and is defined by "the prolongation of the past into the present" so that it is "acting and irreversible."12 Evidently, the dynamic aspect of duration originates from continuity, from its attribute of rolling on itself, of realizing the feature of memory. The process of prolongation is active if the past is indeed conserved, for only then can continuity be real instead of being a mental construct. In other words, as Idella J. Gallagher writes, "duration is all of one piece, an unbroken progress in which the whole of the past is accumulated and preserved and borne along with the present moment."13 Only so conceived can duration be free from subjective confinement.

The continuity of duration eliminates the need to provide qualities with a support that would remain identical throughout changes. Indeed, such a support, which by definition is both fixed and indefinable owing to its distinction from what it supports, would be necessary if time were a discontinuous process. Bergson's entire point is to show that the continuity of duration removes the need for a static support, which need arises from an intellectual representation that divides, for the sake of practical life, what is in reality continuous. Deconstructing the notion of fixed substance, Bergson writes:

As soon as we seek an intellectual representation of it [duration] we line up, one after another, states which have become distinct like the beads of a necklace and therefore require, in order to hold them together, a thread which is neither this nor that, nothing that resembles beads, nothing that resembles anything whatsoever - an empty entity, a simple word. ${ }^{14}$

Because the alleged support is distinct from the states, it is just an abstract notion devoid of characteristics. Inversely, because the states are simply juxtaposed, they do not make up a unified substance, but a sum of disparate elements. A word of caution: Bergson rejects not so much the idea of substance as the idea of fixed, formal, and transcendent substance. In a note protesting against the identification of his view with that of Heraclitus, he 
adds: "let me insist that I am thereby in no way setting aside substance. On the contrary, I affirm the persistence of existences."15 The persistence precisely stems from the continuous interpenetration of elements.

These corrections propose a rethinking of the notion of substance such that it is cleared of its fixity and formal character. The result is the states that the substance is supposed to support, instead of being distinct and juxtaposed, interpenetrate, fuse into each other to form a moving, changing continuity. The substance is one, not because it is above multiplicity, but because it is the indivisible and continuous fusion of all states. In this way, the substance is one and multiple at the same time or oneness is but an indistinct multiplicity. If the flow of time is not one of succession of one state by another state, but their melting into one another, what else is implied but the substantial nature of duration? Neither fixity nor transcendence defines the being of the substance, but the fact that it endures, that is, prolongs all states into one another, thereby persisting while constantly changing. In other words, change does not need a fixed substance for the simple reason that "the permanence of substance" is none other than "the continuity of change." 16

An important point is whether this altered conception of substance applies to what is not conscious, the argument being that only the conscious self is endowed with memory. The answer is yes, since Bergson extends duration to materiality as well in Matter and Memory. In this regard, the book achieves two interrelated results: first, repudiating the prevailing view of perception as a subjective representation, it analyzes perception as an act of selection resulting in objects standing out as distinct, juxtaposed, and fixed entities. The implication is that they have been cut out from a moving continuity in which their apparent and distinct protrusion is dissolved. Second, as an act of selection, perception is no longer a projection of a subjective state: it occurs in the things themselves, the obvious implication being the rejection of the distinction between appearance and reality. ${ }^{17}$ Such is not the case with dualism: the presence of two irreconcilable substances turns perception into a subjective representation, and so necessarily posits the distinction between appearance and reality.

To assert, as Bergson does, that things are perceived in themselves and where they are, is to postulate some affinity between subject and object. More specifically, materiality assumes the form of appearance or manifests its presence under certain conditions, the very ones having to do with the ability of the living brain to insert choice by retarding determinism. This indicates the possibility of transition from materiality to consciousness if determinism, which is the reason for the unconsciousness of matter, is somehow neutralized. And since determinism denotes less the absence of duration than a form of duration not condensed enough to generate novelty, it is plain that the gap between matter and mind originates from the nature of their respective level of condensation or memory. Unable to condense its 
various moments and hence to change by merging passed states into the present, matter simply spreads out and repeats the present. By contrast, the mind is capable of blending all its moments with the present so that, instead of being extended and repetitive, its moments form an indivisible, unextended, and, for that matter, creative unity.

The extension of memory to materiality provides a platform for tackling the issue of the union of mind and body by establishing that both retain the past, though in different ways. The body preserves the past in the form of impersonal and nascent motor activities, which Bergson calls habit or motor memory and whose characteristic is to trigger attitudes of automatic responses. The mind, on the other hand, in addition to preserving the past in the form of myself, that is, condensed and unextended, has the ability to selectively recall and represent it by using the motor habits of the body. The unity of mind and body is thus none other than the synchronization of the two memories: in the words of Bergson, the past is "acted by matter, imagined by mind." 18 The nascent actions of the body, felt as sensations, affections within the body, provide the sensuous framework upon which the mind imagines, that is, converts pure memory into memoryimages. Affection results from the combination of the general property of material objects to act and react with the preservation of selected reactions. We find its most elementary appearance in the contractibility of the amoeba, which shows a rudimentary form of selective reaction. The development of the nervous system intensifies and centralizes the storage of automatic responses so that the schemes of possible movements are felt before the execution of actions. In thus storing reactions in the form of felt motor habits, the body develops the power to anticipate and initiate, thereby changing reactions into chosen actions.

The framework of the mind imagining what the body is sketching in terms of motility seems to establish an equivalence that strongly pulls the Bergsonian explanation in the direction of monistic parallelism, perhaps even toward materialism. Such would have been indeed the case were it not that duration generates differences in kind. In particular, what is wrong with materialism is that it wants to generate higher forms by using the mechanical laws governing the lower level of reality. In so doing, it misses the nature of matter as a loss of tension, as a duration juxtaposing its contents in default of condensing or merging them into one another. Accordingly, there cannot be any equivalence between the body, whose mode of being is confined, as any material object, to "a present which is always beginning again" and the enduring, condensed present of the mind. ${ }^{19}$ To use Bergson's metaphor, "the work of the brain is to the whole of conscious life what the movements of the conductor's baton are to the orchestral symphony." 20 Because the mind always overflows the body, their relationship is one of synchronization for the benefit of practical life. Instead 
of one-to-one correspondence, we have an act by which the mind compresses itself to present its useful side.

What all this signifies is that intensification is the road from materiality to spirit: that which tends to separate and extend does so because it is much less intense, and its dispersion is how it chains itself to necessity and unconsciousness. By contrast, just as the brightness of a flashlight intensifies the more the surface it covers narrows, that which tends to condense gains in intensity and consequently in sensitivity and spontaneity. The prolongation of the past into the present ascertains a higher level of condensation of duration, while juxtaposition and repetition point to the loss of the condensing attribute, obvious as it is that repetition denotes a lax, spreading unity.

That Bergson takes what modern thinking considers as absolutely subjective, namely, time, and turns it into the very stuff of reality may look as a defiance that is difficult, if not impossible, to uphold. Yet, if objectivity signifies whatever is independent of the will of the perceiver, it is hard to encounter an experience that is as independent of our will as duration. Going against the mechanical view of matter, Bergson gives us a sense of the duration of material things when he notes that he has, perforce, to wait for the dissolution to take place each time he mixes sugar with water. The waiting has a metaphysical meaning, for "it coincides with my impatience, that is to say, with a certain portion of my own duration, which I cannot protract or contract as I like. It is no longer something thought, it is something lived. It is no longer a relation, it is an absolute." 21 Stated otherwise, the waiting is not a merely subjective, psychological process; it is the revelation of an objective duration, since I am waiting despite my impatience. What else can my powerlessness to impact on my waiting indicate but that "the glass of water, the sugar, and the process of the sugar's melting in the water are abstractions, and that the Whole within which they have been cut out by my senses and understanding progresses, it may be in the manner of a consciousness?" 22

Two crucial facts are stated here: (1) distinct things, such glass, water, sugar, etc., ensue from an act of selection and immobilization; (2) their insertion into the Whole to which they belong turns the melting of sugar into a process, a becoming, which has little to do with the representation of a cause mechanically producing the effect of melting. Indeed, where distinct objects are supposed to exist, change and movement can only be conceived as mechanical outcomes, the reason being that separation presents changes as effects of mechanical encounters, and not as internal self-alterations. Conversely, if continuity is restored, change becomes a qualitative alteration, an internal evolution instead of being a product of mechanical displacement. Conceived as a change of state, the melting of sugar assumes the character of an event to which the entire universe participates even if, for practical purpose, I confine its occurrence to a mechanical encounter between the 
glass of water and the sugar. Consequently, once distinct things are made to dissolve into the mobility of reality, whatever happens is no longer isolable from the universe. To the extent that this continuity of all things reveals the unity of materiality whose internal progressions produce material phenomena, it is akin to the experience that we have of our own duration. The obvious conclusion is that "my duration both encompasses and discloses other durations." 23

The dissolution of distinct objects and the restoration of continuity to matter provide a solid support for "the comprehension of the material universe as being of the same nature as the self." 24 But then, our effort to rescue Bergsonism from the monist temptation seems to fail. If matter is a unity of multiplicity, just as the self, where is the radical difference that would support dualism? The more duration is supposed to be the common attribute of matter and spirit, the less there is place for dualism. Yet, Bergson never disavowed dualism; he even described Matter and Memory as "frankly dualistic," it is true, with a major specification, which is that the book wants "to lessen greatly, if not to overcome, the theoretical difficulties which have always beset dualism." 25 What additional considerations can help us frame the way durational monism accommodates dualism while removing the traditional difficulties?

\section{From Monism to Dualism via Intensity}

First let us clarify the difficulty facing Bergsonism. Even as we note how difficult the integration of dualism into the system of durational monism is bound to be, for many scholars it is the overcoming of traditional dualism that seems an impossible task in view of the numerous dualisms encumbering Bergsonism. The oppositions between space and time, quantity and quality, matter and memory, to name a few, practically define the system. Granted the difficulty of integrating these oppositions into a monistic philosophy, it is even harder to defend dualism by recovering these oppositions once they have been incorporated into a monistic system. Worse still, the integration of materiality and mind through considerations of expansion and condensation raises the question of knowing whether such types of movement can result in a difference justifying the assertion of dualism.

This much we know: Bergson replaces the dualistic notion of separate substances with the notion of differences in kind. Differentiation avoids separation, since what is tense is not alien to what is relaxed. Nonetheless, it is also far from clear how differences in tension, in so far as they can be scaled down to the quantitative difference of less and more, can yield differences in kind of the dualistic type. How can the dualism of different rhythms of duration match the dualism of substances? In a monistic system, the transformation of quantity into quality makes sense, and Bergson 
himself has gone a long way in showing its viability. Thus, Matter and Memory points out that, without the condensing power of memory, "the sensation of red light, experienced by us in the course of a second corresponds in itself to a succession of phenomena which [...] would occupy more than 250 centuries of our history." 26 This transformation of quantity into quality through condensation avoids subjectivism: qualities are in the things themselves, though in a diluted form, and contraction does not change the nature of things. In short, we have here a mere act of intensification that does not implicate any substantial transmutation.

Quite aware of the difficulty of passing from intensification to dualistic differences, Gilles Deleuze cannot but wonder whether "there is not a contradiction between [...] the dualism of differences in kind and the monism of contraction-relaxation." 27 After all, to say that differences are due to relaxation and contraction seems to imply that both acts are accountable in terms of more or less intensity, which is itself expressive of a quantitative notion. Deleuze struggles to remove the apparent contradiction by arguing that dualism is "only a moment, which must lead to the re-formation of a monism." 28 He supports the interpretation by the argument that Bergson, who strongly criticized the use of the notion of intensity for mental states in his first book, "recognizes," in his second book, "intensities, degrees or vibrations in the qualities that we live as such outside ourselves and that, as such belong to matter. These are numbers enclosed in qualities, intensities included in matter." 29 Quantity is not devoid of quality; it is simply less intense. This connection between quantity, intensity, and quality, as demonstrated by the sensation of red light, affirms dualism and reinstates monism. It affirms dualism through the attribution of differences in kind to intensity, which at its lowest degree is none other than materiality.

The rapprochement between the mental and the material on the basis of intensity thus asserts (1) dualism in the form of two tendencies, the one delivering differences in kind and the other differences of degree; (2) a reformed monism, since differences in kind represent different degrees of condensation within the same nature, thereby accommodating dualism in the form of differences in kind without, however, being substantial, as in traditional dualism. To quote Deleuze, "All the degrees coexist in a single Nature that is expressed, on the one hand, in differences in kind, and on the other, in differences in degree. This is the moment of monism. All the degrees coexist in a single Time, which is nature itself." 30 With one duration differentiated by levels or degrees of condensation, the contradiction between dualism and monism disappears: qualities represent different degrees of condensation of the same single time into which they are, accordingly, integrated. We do not have memory on one side and matter on the other, but one single duration differentiated by coexisting levels of condensation. To posit one single time or memory means that things are different by their levels of contraction and that their coexistence forms a 
whole that remains virtual, since what each level actualizes of the totality is only a perspective. So conceived, dualism ceases to signify transcendence and turns into a moment of a monism integrating quantity and quality. This integration eliminates the reductionist nature of traditional monism, which reduces quality to quantity in its materialist version and does the opposite in its idealist version.

In thus pulling Bergson toward the affirmation of one Time or Memory and the interpretation of intensity as a reconciliation of quality and quantity, Deleuze certainly gives a powerful interpretation that removes the alleged contradiction. Unfortunately, he does so at the expense of a crucial component of Bergson's philosophy, namely, the commitment to substantial dualism. Unsurprisingly, the interpretation has raised objections from various authors. Thus, Stéphane Madelrieux speaks of "de-spiritualizing Bergson to make him again actual in the age of anti-humanism." 31 Nathan Wider reminds that all of Bergson's attempts to overcome the difficulties of dualism "maintain the priority of quality over quantity, which serves to sustain Bergson's assertions of duration's continuity and ego's purdurance." 32 In other words, what the Deleuzian interpretation overlooks is that the mind, though initially inserted into materiality, attains autonomy. For Bergson, dualism is not merely a moment leading to a reformed monism; it is an ontological emancipation from materiality. True, dualism is no longer a point of departure, as in classical dualism, but it is definitively a point of arrival, precisely as a breakaway from the automatism of matter. Though Deleuze is correct in underlining the monism of Bergson, he goes astray with an interpretation that has no room for the transcendence of the mind. For Deleuze, just as matter is never extended enough to become space, likewise "duration is never contracted enough to be independent of the internal matter where it operates, and the extension that it comes to contract." 33 In short, however intense contraction may be, it cannot do away with a material content, on which it always operates.

One of the merits of Deleuze's interpretation is to highlight the novelty of the approach replacing the traditional notion of distinct substances with that of differences in kind. The notion of differentiation allows the derivation of differences in kind from the same unit, and so achieves the integration of quantity and quality. This possibility of derivation certainly decreases the difficulties of traditional dualism. However, Deleuze saw contradiction in the Bergsonian interpretation of differences in kind in the direction of traditional dualism. For him, the only way to avoid the contradiction is to convert dualism into a moment of monism. In arguing that the contradiction cannot be overcome unless dualism returns to monism, Deleuze breaks away from Bergson's attempt to reform dualism in such a way that it becomes a product of monism instead of excluding it. 


\section{Duration and Dialectics}

The Hegelian process of negation of the negation offered Bergson a way for resolving the contradiction between dualism and monism without reductionism or falling back into traditional dualism. It posits dualism and monism as contradictory terms and the resolution of the contradiction as a synthesis effected through the negation of the first negation. Thus, dualism first negates monism during which it asserts and develops itself until it is negated and integrated into a developed monism. Since the first negation represents a split within the unity of being, it necessarily calls for the second negation to reconstitute the original unity, thereby ending its one-sidedness. In effect, Hegel unifies quality and quantity by noting that increase or decrease affects quality only when it reaches a certain limit. The limit represents the "measure" of the thing, which as a unity of quantity and quality, "is a qualitative quantity." 34 Quantity first negates quality by increasing or decreasing unilaterally until the limit is reached when reintegration occurs through a qualitative change.

According to Deleuze, Bergson rejects the dialectical solution because the integration privileges the affirmation of identity at the expense of difference. The synthesis turns difference into a mere moment of the development of the original unity. As Anne Sauvagnargues puts it, both Deleuze and Bergson resent "the dialectic synthesis of opposites that absorbs disparity in some higher unity." 35 Indeed, opposing terms that are originally one generate unilaterality, and so necessitate synthesis, that is, the absorption of the two in a developed unity. For Bergson, however, development is not how unity asserts itself through internal contradiction, but how it generates irreducible differences. Moreover, opposition is an abstract approach, whereas reality mixes genres in various dosages, and so displays nuances or grades rather than exclusive polarizations. Because opposition captures real differences abstractly, it forgets that the differences belong to the continuity of nature. By contrast, differentiation involves grades, which respect the continuity of nature while achieving real differences. For example, what is real is not the opposition between day and night, but the various nuances or qualitative differentiations laid out between the two extremes. Hailing Bergson's opposition to dialectics, Deleuze writes, "To reach a conception of difference without negation, which does not contain the negative-such is Bergson's greatest effort." 36 Difference becomes real, and not a mere moment or device, only if it results from an act of creation: what is invented is absolutely new and did not exist previously in any form so that it cannot be reintegrated into a prior matrix. In the words of Bergson, in creation "there is radical contingency in progress, incommensurability between what goes before and what follows-in short, duration." 37 The involvement of an act of creation means that what follows does not simply unfold from what precedes: it takes time because it is invented. 
As fusion, indistinct multiplicity, duration is precisely that which can differentiate without contradiction, for its original plurality engages it on divergent lines, which remove the need to reconstitute its unity or resolve its contradiction through synthesis. Difference is not an opposite, but a creation, so that the restoration of unity is never a target. The unity remains behind, which means that the process, instead of being teleological, is dissociative, with the understanding that the dissociated element retains the original unity virtually. Just like "the wind at a street corner divides into diverging currents which are all one and the same gust," so too in the evolution of life, "harmony is rather behind us than before. It is due to an identity of impulsion and not to a common aspiration." 38 Being "a unity that is multiple and a multiplicity that is one," the creative force of life, which Bergson calls the vital impulse (élan vital), individualizes by accentuating, spatializing a tendency that retains the multiple unity of the impulse virtually. 39

The nature of duration itself thus suggests how to approach the conflict between dualism and monism. Opposition always presupposes abstraction, since it ignores the nuances and mixtures of reality in favor of extreme polarization. That is why opposing terms with the hope of prevailing by means of synthesis is fruitless: each of the opposing terms "applies partially to reality since it is extracted from it," with the consequence that the dialectical debate can go on endlessly. 40 The way out is to "create superior concepts in which the old oppositions are absorbed." 41 The concept of vital impulse is a perfect example of this: it presents reality, not as being either material or mental, or separately material and mental, but in the words of Bergson, as "a reality which is making itself in a reality which is unmaking itself." 42 Life, which is of a psychological nature, is an impulse because it confronts matter as an inverse movement of its own. Consequently, the vital impulse is a mixture of the mental and material: we do not have matter on the one hand and mind on the other, but an enduring movement, which represents an internal effort to inverse a descending trend toward materiality. What in principle should have been an automatic, instantaneous deployment endures because an inversed effort is passing through it. When it is successful, the inversion materializes in the form of living organisms.

No one should rush to point out contradiction on the grounds that the positing of two movements that are inverse of each other draws Bergson into the Hegelian method of thinking. The process, as already stated, is creative, and so does not lead to synthetic reconciliation emanating from a second negation, as is the case with dialectical thinking. More importantly, the terms do not constitute a unity of opposites moving along a teleological path. Instead, it is an inversed relationship that takes the original unity toward divergent paths and increasingly widens the gap between the terms instead of narrowing it. Consequently, even though Bergson often opposes 
matter to life and spirit, they never form opposite couples for the simple reason that they are inverse of each other. As such, they never unite but diverge, even to the extent of generating duality, given that the one direction rolls on itself while the other spreads out. What results from movements that are in an inverse relationship is not unification, but an impulse, the very one trying to overcome a resistance. It is my contention that Deleuze's fear of contradiction in the Bergsonian treatment of quantity and quality dissipates as soon as we recognize that the degrees of condensation structuring duration occur in an ontological context defined by a movement inversing a descending direction.

\section{The Slanted Reality}

It is clear that inversion promotes monism, since it is not about two different substances opposing externally each other, but the same substance that inverses itself. The descending direction is that of materiality: though in principle the movement should have yielded an instantaneous outcome, it is slowed by its inverse movement. Indeed, not only that which descends or relaxes must have been first tense, but also the relaxation must retain something of the original tension, which then prevents complete relaxation. The slowing gives us the lowest degree of condensation of duration. It follows that, wherever there is a successful breakthrough of the passage of the inverse movement, the level of concentration increases to the benefit of qualitative change. Understandably, while being of similar nature, inversion of a descending trend achieves more than the descending trend.

When Deleuze suggests that quality "is nothing other than contracted quantity," he is correct, on one condition, namely, that such an outcome presupposes the presence of an inverse movement, the very one retarding the descending movement of matter. ${ }^{43}$ What this means is that contraction and relaxation are not distinguished by their intensity only, but also by directions inverse to each other. Contraction is not only more intense; it is also the inverse of relaxation. There is transition from quantity to quality, not just because of contraction, but because contraction occurs on the ascending tendency of reality.

Only through the recognition of tendencies inverse of each other can one avoid the difficulties facing dialectics. Hegel and Marxist dialecticians tried to account for the transformation of quantity into quality by the notion of leap. Because it is not quite clear how increase or decrease can lead at a definite point to a qualitative change instead of yielding more or less of the same, Hegel talked of leaps in nature to explain the sudden discontinuity caused by qualitative change. He writes, "With the increase of diminution of the temperature of the liquid water, there comes a point where this state of cohesion suffers a qualitative change, and the water is converted into steam or ice." 44 My point is not to deny the existence of leaps in nature, but to 
pinpoint that the explanation of their occurrence becomes plausible if the presence of an inverse tendency is first admitted. From quantity, however one increases or decreases it, qualitative change cannot emerge unless quantity is taken up by an ascending movement. To the extent that the descending movement expands and scatters, the re-climbing movement gathers and condenses what is scattered. What else can an ascending movement be but the very one that collects and hence intensifies what is spread out?

It is easy to counter the objection according to which an appeal to an ascending movement excludes qualitative changes occurring within materiality. The objection simply forgets that life is not externally or accidentally added to materiality. As a delayed descending movement representing the lowest degree of concentration of duration, materiality is inseparable from life. Without life slowing its fall, materiality would turn into pure space. Given within materiality, the ascending tendency is simply diluted, stretched out owing to the descending trend. Unable to completely reverse the process except to slow the tendency to spatialize, life divided itself into living beings, for only thus could it to pass through the cracks offered by materiality. This suspended fall explains why purely quantitative changes can suddenly yield qualitative changes: materiality possesses a rudimentary level of condensation able of qualitative modification, even if it does not reach the intensity of living organisms.

To say intensification with qualitative outcome is hardly imaginable without inversion basically means that the ascending movement injects continuity. Consequently, the more the continuity is condensed, the higher is the qualitative change. In what simply increases or decreases, whatever changes occur, the elements remain distinct and separate, and so never reach the level of organization. There is never enough to conquer some autonomy in relation to materiality (autonomy here implies the achievement of individuation). The low level of qualitative change that occurs in a given material object is not due to the object itself, but to the duration of materiality as a whole. Since the object is only an artificial cut, its change implicates the totality and, as such, it is not so much a mechanical phenomenon as a durational outcome, even if it is of the lowest level of compression. Thus, increasing the heat changes the cohesion of the molecules of water at a definite point, and not instantaneously, because the heat and the water cannot be isolated from the rest of materiality.

The case is different with a system isolated by nature, as is the living organism: unlike the artificial objects cut out by our intelligence, the living organism is relatively insulated from the whole of materiality. This relative isolation generates organic individuation by reaching a level of condensation in which the past acts on the present, thereby assigning to change irreversibility or a directional trend going through different stages of maturation and old age. In materiality as a whole, relaxation obstructs the 
prolongation of the past into the present and changes continuity into repetition. Irreversibility appears when the level of condensation or (which is the same thing) of organization is such that the past prolonging into the present imprints an evolutionary direction of change. Unlike material objects whose change is explained by what happened immediately before, which is just another present, organic change is cumulative and accordingly results in higher qualitative transformations. Such a change is directional because it has continuity, memory; it "has a history," in the words of Bergson. ${ }^{45}$

The conclusion is that Bergson does transcend monism and dualism by this notion of inverse movement. Instead of opposing monism to dualism, inversion shows how monism by its own nature produces dualism. The latter becomes a product if monism is itself a movement defined by two directions inverse of one another. While the descending direction separates, divides, the ascending trend organizes, condenses, thereby producing differences in kind in higher and higher forms up to the level of pure memory or immaterialism. Bergson's definition of life as an effort "to remount the incline that matter descends" gives us both the unity of substance and the inverse outcome of dualism. ${ }^{46}$

This understanding of materiality as a fall delayed by an ascending tendency is also how Bergson avoids pantheism. Just as for an original monism to yield dualism an inverse movement is necessary, so too the loss of tension that generates materiality posits a center of such immense concentration that materiality flows out from it. How else could the peak level of tension be defined but as a relaxing movement that contracts to the point of ejecting materiality out of itself? For Bergson, God is indeed a "center from which worlds shoot out like rockets in a fire-works display." 47 The notion of tension and the subsequent implication of a peak level enable Bergson to defend a monism that does not identify God and nature, as does Spinoza, given that the loss of tension inserts an impassable gap between God and what derives from God. The same notion also shows how the subsisting tension retards the fall of matter and realizes itself as an impulse, "an effort to raise the weight which falls." 48 This image of reality as an incline, as a slanted being reconciles, more exactly transcends dualism and monism. Reality does not oppose two substances since the slope is one; nor does it negate dualism, since the descent is never the equivalent of the ascent. Though the same reality is involved in both cases, different results are obtained: the one expands, the other condenses. Condensation lifts differences in degrees to the level of differences in kind and even to the point of duality, thereby reaching the stage of autonomy. The inversion of a descending process thus accounts for the emergence of dualism from monism itself: at first fused within the original unity, the two directions progressively diverge and separate without, however, becoming alien to each other. 
Accordingly, rather than "moving from dualism to monism," as Deleuze has said, Bergson moves from monism to dualism, notably in Creative Evolution.49 At first glance, this conclusion appears to be a confirmation of Vladimir Jankélévitch's characterization of Bergsonism as "a monism of substance, a dualism of tendencies."50 On closer examination, however, the difference is that Jankélévitch simply juxtaposes monism to dualism. His conception first poses substance in its traditional understanding and the dualism of tendency is added to it. As a result, Bergson is not credited with a reformed conception of substance, that is, with a conception of the substance as dual in its very oneness. The downside of this interpretation is that it weakens Bergson's commitment to dualism by failing to incorporate dualism into the substance in the form of inverse movement. In my view, what primarily defines the spirit of Bergsonism is the idea of emancipation, freedom from an initial insertion into the whole. Freedom is not a primary attribute; it is conquest over determinism. Bergson criticized the traditional view for ignoring this initial insertion, not for defending dualism.

If dualism is not an added attribute, if it is inherent in the substance conceived of as a delayed fall, such a conception lands us nowhere but in a vitalist ontology. The notion of slanted substance, which signifies the making of a reality on the basis of its own unmaking, posits dualism both as an outcome and an inherence. It is life itself in as much as life has the two sides of passivity and activity, materiality and impetus. What remains now is the question of knowing to what extent the vitalism of inverse movement measures up to a conception exhibiting a striking similarity, to wit, Nietzsche's ontology.

\section{The Slanted versus the Tidal}

Arnaud François and other scholars have called our attention to the remarkable similarity between Bergson's conception of life and that of Nietzsche. Notwithstanding other differences, François sees "an astonishing convergence of movements" in the fact that "Nietzsche and Bergson come to characterize life in terms of 'will to power' for the former, and 'élan' for the latter."'51 For both of them, neither self-preservation nor adaptation to external circumstances defines the essence of life. Moreover, both propose an ontology of the will that posits a movement with two directions running counter to each other. We will first analyze the convergence between the two philosophers so as to mark out clearly the moment of irreconcilable divergence.

The fundamental agreement leading to other remarkable similitudes stems from the commitment to "the thesis of the univocity of being." 52 Convinced that the impasse of traditional dualism and monism originates from a faulty ontology, Nietzsche and Bergson advocate the need for a new 
approach to being that it would overcome the traditional oppositions. One important consequence of the univocity of being is that both philosophers reject the distinction between being and appearance. If being is one, nothing is merely subjective so that what is out there, external to us cannot be anything other than what is in us. It follows that the real is what is given, and not what is behind the given. One basic condition for overcoming the opposition between being and appearance is the rejection of the mechanical conception of matter. We saw how Bergson's extension of duration to matter effectively lays the groundwork for an integrative ontology. For his part, Nietzsche specifically rejects the mechanical conception: he argues that mechanical notions embody our values so that "this world is the will to power--and nothing besides!" 53

The interesting outcome here is that, although at first glance duration and the will to power seem quite distant, they converge on the idea that life is reality. In describing the real as the inversion of a descending movement, as an élan confronting its own inverse movement, Bergson thinks life as an effort, a will. "The vital," Bergson claims, "is in the direction of the voluntary" because the order of "the vital or of the willed" is opposed to "that of the inert and the automatic." 54 The presence of two inseparable and inverse orders posits life as a drive to overcome itself, to draw from itself more than there is originally and, hence, as a creative force. To say there is a will wherever a movement counters an inverse tendency that is internally given is to confirm that reality is made of the oneness of the two movements. This oneness shapes life as an impetus overcoming a resistance, that is, as a phenomenon echoing the voluntary. Besides, it is hardly surprising that Bergson defines reality as life, given the central role assigned to the movements of tension and relaxation: the tenser the movement, the more it naturally tends toward willing, just as the more relaxed it is, the more it turns into resistance.

For Nietzsche, too, life confronts and overcomes internal resistance. It is will to power, and as such constantly strives to increase power. Life is will means that the need to overcome, to subordinate a resistance that can only be another will of a lower degree defines it, obvious as it is that "'will' can naturally have effects only on will--and not on 'matter.'"55 Consequently, the vision of matter as a mechanical reality is just an expression of the will to power: the aspiration to dominate constructs matter as a mechanical reality formed of inert and distinct objects or, as Nietzsche puts it, "all the presuppositions of mechanistic theory--matter, atom, gravity, pressure and stress--are not 'facts-in-themselves' but interpretations with the aid of psychical fictions." 56 Be it noted that Bergson maintains the similar view that "our perception [...] cuts inert matter into distinct bodies." 57 The vision of distinct bodies does not describe the true, objective world; it is a construct reflecting our needs and methods of action. The conclusion is that the organic and materiality as a whole are not different in their nature, except 
for the fact that the organic is isolated by nature itself and that materiality constitutes an organic whole of a lower order compared to the organic.

To the extent that this conception of reality as power relations fills the ontological gap between the organic and the inorganic, it establishes a monistic vision that avoids the difficulties of the traditional approaches. The concept of the will to power transcends mere mechanism, and so wards off the drawbacks of monistic materialism. Likewise, the world as a manifestation of the will to power counters the reduction of reality to thinking, which is characteristic of monistic idealism. Finally, in relating differences in kind to different intensities of will, the concept accounts for transitions from lower to higher levels of will within the same reality, thereby overcoming the difficulties of dualism. We saw a similar method of thinking with Bergson, to wit, the use of a concept (duration) able to absorb the traditional oppositions between dualistic and monistic philosophies.

Despite the similarity of their methods, the difference between the two thinkers is nonetheless apparent, as Bergson draws the unity of being from duration instead of from the will to power. The use of different totalizing concepts tells us that their undeniable similarities occur on diverging lines of thought. To begin with, Nietzsche does not have any of the ambiguities of Bergson in that he is consistently monist. For him, dualism does not need to be recovered because it is a mistake, more precisely an illusion. That is why he does not engage in the path of Bergson's continuist and ascending conception of time, which can only grant perenniality to what Nietzsche considers to be an illusion. In effect, Nietzsche proposes a discontinuist conception according to which the reality being made is also constantly being unmade. The eternal recurrence is this power to construct and deconstruct the world. This means that recurrence is not the theory that events will recur again and again infinitely; rather, it is the opposite in that their recurrence makes sure that only what is new or different comes into existence. It is, so to speak, a method of recapitulation by which continuity is perpetually interrupted and amended in the form of a transient present. Accordingly, the point of bifurcation between Bergson and Nietzsche lies in their understanding of time: the one thinks time as duration, the other as eternal recurrence.

For Bergson, duration is defined by the prolongation of the past into the present, which prolongation determines the intensity or the various degrees of condensation ranging from spirit to materiality, the lowest level of condensation. Moreover, the intensification process occurs on the ascending direction of reality, which leads to increasing divergence, and finally to the autonomy of the conscious self. This genesis of a dualist outcome from an original oneness is consistent with the process of intensification, given that the highest level of condensation can only be a complete merger in the form of self-consciousness. Nietzsche, however, retorts that the ego is just an impression, and not a substance, an enduring 
reality. The perception of the self as an entity is simply a useful fiction and, as such, an interpretation of the will to power. It is how "the ego counts as a substance, as the cause of all deeds, as a doer," and so flatters itself by elevating itself to the status of a free and sovereign agent. 58 The reasoning that attributes the distinct identity of objects to our needs should equally apply to the ego: if the belief in the existence of distinct objects is a fiction necessary for life, so is the belief in the subject. To be precise, the identity of objects depends on the "ego," for "all other 'being' is fashioned after its mode." 59 It is therefore inconsistent of Bergson to revoke the identity of objects save that of the ego.

In thinking the ego as a fiction, Nietzsche naturally removes all agency from consciousness in favor of a deterministic approach. While Bergson contends that consciousness appears where determinism has been deactivated, Nietzsche remains insensitive to the argument that the appearance of consciousness in a determined process makes no sense at all. The removal of freedom forces Nietzsche to think "consciousness in a subsidiary role, almost indifferent, superfluous, perhaps destined to vanish and give way to a perfect automatism." 60 All this is to say that the defense of monism by excluding dualism remains distinct from the Bergsonian attempt to transcend both monism and dualism. For Bergson, so long as a theory does not accommodate dualism, it is just another version of the old monism and, as such, falls short of considering all the elements of the problem. One does not see how reductionism is avoided unless monism gives birth to dualism.

Nietzsche's purpose is less to integrate dualism than to extirpate it once and for all by subordinating the will to power to the law of eternal recurrence. His argument is that eternal recurrence is itself an expression of the will to power. Since the will is defined by the need to constantly overcome itself, it does not pursue any permanent form. Instead, it is by constantly destroying what it is achieving that it can continue to aspire for more power. However, destruction becomes expressive of the will to power only through a recurring process: it achieves more when the process is reset through recurrence, otherwise it would be chaotic and hence contrary to the will to power. Just as failing to lift a heavy object encourages starting again with more intensified effort, the will constantly restarts where it left off and in doing so renovates and achieves more.

In Nietzsche's view, recurrence is the law because the will to power is neither a created reality nor a teleological process, still less an infinite force. For him, this world is "a monster of energy, without beginning, without end; a firm, iron magnitude of force that does not grow bigger or smaller, that does not expend itself but only transforms itself." 61 The image of the ebbing and flowing tide best describes such a world. To postulate a tidal movement means that the word is not an infinite force, since it exhausts itself and must ebb to regenerate itself; nor is it a created reality, as it is devoid of purpose. 
How can it harbor goals if it mercilessly destroys what it creates? In ebbing and flowing, it generates opportunity, not as an implicitly given possibility, but rather as "the great dice game of existence," and as such is devoid of any continuity. ${ }^{62}$ Just as the same dices thrown repeatedly reappear with new numbers, so too life repeats and renews each moment. For Bergson, however, it is not discontinuity, but the prolongation of the past into the present, the condensing attribute of memory that explains the novelty of each passing moment. Prolongation achieves novelty by deploying a continuous, cumulative forward movement; the Nietzschean notion achieves a similar result by positing a discontinuous recasting movement.

We thus come back to the great divergence between Bergson and Nietzsche, namely, the issue of continuity. Although we still find affinities in the fact that Bergson's rejection of the ideas of nothingness and possibility seems to concur with Nietzsche's view of an uncreated and non-teleological world--not to mention that for both thinkers the force animating the world is finite--a vast abyss actually separates the similarities. The ebb and flow of the eternal recurrence has no place for continuity, that is, for a reality being made on the basis of a movement unmaking itself. What is made is itself unmade so that the genesis of dualism from monism is never achieved.

In speaking of an inverse movement that he specially termed "élan," a sustained forward movement, Bergson rejects the tidal movement and posits a flow that does not ebb. True, the élan is finite, but only because it remains trapped in its own inverse movement, even where it succeeds in assuming some degree of autonomy. Equally true is the fact that the élan does not proceed teleologically, for it is not so much goal-oriented as it is an impulse, a push from behind so that what is in front, the future remains undetermined. In other words, the élan does not realize a preconceived plan but remains creative throughout. Still, as an élan, and this is what is crucial for Bergson, inverse movement persistently pushes forward and saves what it has achieved as a stepping stone to move further.

For Bergson, the world does not play the Dionysian game of eternally doing and eternally undoing; it is rather like Homer's protagonist Odysseus, "the man of twists and turns," continually advancing forward. He writes, "Life [...] transcends finality as it transcends the other categories. It is essentially a current sent through matter, drawing from it what it can." 63 Since the élan is unable to instantaneously inverse the descending movement, it proceeds successively and cumulatively. It is thus duration: not only does it continue pushing forward against the descending direction, but it also totalizes the results, thereby obtaining qualitatively evolving changes. Put otherwise, it rises to genuine creativity by bringing to life what did not exist previously, among other things its highest product, namely, the mind, the autonomous self. 
To summarize, Nietzsche and Bergson posit a recurring or repetitive movement, with the major difference that for Nietzsche the movement covers a horizontal or flat ground, while Bergson speaks of an inclined terrain requiring an ascending movement. As a collecting movement, the latter never begins again because it proceeds with cumulative continuity and creativity. Herein lies the Bergsonian revolution. Time is not what passes, and hence requires a fixed substance. Time is not continuous discontinuity or recurrence, either. Rather, time is what endures through an undoing. Where two inseparable and inverse movements operate, philosophers saw only what passes or repeats at the expense of what is being made. Understood as duration, time is genesis, that is, the being-made, as opposed to what passes, unfolds, or simply subsists.

${ }^{1}$ Arnaud François, “Ce que Bergson entend par 'monisme': Bergson et Haeckel,” Lire Bergson, eds. Frederic Worms and Camille Riquier (Paris: Quadrige/PUF, 2011), 121 (my translation).

2 George Berkeley, A Treatise Concerning the Principles of Human Knowledge (New York: Dover Publications, Inc., 2003), 46.

${ }^{3}$ Rene Descartes, Meditations on First Philosophy (New York: Routledge, 1993), 97.

${ }^{4}$ Henri Bergson, "The Soul and the Body," Mind-Energy, trans. H. Wildon Carr (New York: Henri Holt and Company, 1920), 73.

${ }^{5}$ François, “Ce que Bergson entend par ‘monisme’: Bergson et Hackel,” 136.

${ }^{6}$ Henri Bergson, "The Metaphysics of Life: From Leçons de Psychologie et de Métaphysique given at Clermont-Ferrand, 1887-88,” trans. Michael Vaughan, SubStance 36.3 (2007): 26.

${ }^{7}$ Henri Bergson, Time and free Will, trans. F. L. Pogson (New York: The Macmillan Co. 1921), 121.

${ }^{8}$ Pierre Montebello, “Differences de la nature et differences de nature,” Bergson: la durée et la nature, ed. Jean-Louis Vieillard-Baron (Paris: Presses Universitaires de France, 2004), 144 (my translation).

${ }^{9}$ Henri Bergson, Creative Evolution, trans. Arthur Mitchell (New York: The Modern Library, 1944), 292.

${ }^{10}$ Ibid., 393.

11 See Messay Kebede, “Action and Forgetting: Bergson's Theory of Memory,” Philosophy Today 60, no. 2 (2016).

${ }^{12}$ Bergson, Creative Evolution, 20.

13 Idella J. Gallagher, Morality in Evolution: The Moral Philosophy of Henri Bergson (The Hague: Martinus Nijhoff, 1970), 19

${ }^{14}$ Henri Bergson, “Introduction II," Creative Mind: An Introduction to Metaphysics, trans. Mabelle L. Andison (New York: Dover Publications, Inc., 2007), 55.

${ }^{15}$ Bergson, “Introduction to Metaphysics," Creative Mind, 222. 
${ }^{16}$ Bergson, “Introduction II," 70.

17 See Messay Kebede, “From Perception to Subject: The Bergsonian Reversal," Journal of French and Francophone Philosophy 23.1 (2014).

${ }^{18}$ Henri Bergson, Matter and Memory, trans. Nancy Margaret Paul and W. Scott Palmer (New York; The Macmillan Co., 1919), 298.

19 Ibid., 279.

${ }^{20}$ Bergson, "The Soul and the Body," Mind-Energy, 58.

${ }^{21}$ Bergson, Creative Evolution, 12-13.

22 Ibid., 13.

${ }^{23}$ Keith Ansell-Pearson, Philosophy and the Adventure of the Virtual: Bergson and the Time of Life (New York: Routledge, 2002), 10.

${ }^{24}$ Pierre Montebello, “Matter and Light in Bergson's Creative Evolution,” SubStance 36 (2007): 91.

${ }^{25}$ Bergson, Matter and Memory, vii.

26 Ibid., 273.

27 Gilles Deleuze, Bergsonism, trans. Hugh Tomlinson and Barbara Habberjam (New York: Zone Books, 1988), 75.

28 lbid., 29.

29 lbid., 92.

30 lbid., 93.

31 Stéphane Madelrieux, “Lire James, relire Bergson,” Lire Bergson, 103 (my translation).

32 Nathan Wider, “Deleuze on Bergsonian Duration and Nietzsche's Eternal Return," Time and History in Deleuze and Serres, ed. Bernd Herzogenrath (London: Continuum Studies in Continental Philosophy, 2012), 129.

${ }^{33}$ Deleuze, Bergsonism, 88.

${ }^{34}$ Georg Wilhelm Friedrich Hegel, Hegel's Logic, trans. William Wallace (Ohio: Bookmasters, Inc., 2009), 222.

35 Anne Sauvagnargues, “Hegel and Deleuze: Difference or Contradiction?" Hegel and Deleuze: Together Again for the First Time, eds. Karen Houle and Jim Vernon (Evanston: Ill.: Northwestern University Press, 2013), 40.

${ }^{36}$ Gilles Deleuze, “Bergson's Conception of Difference," trans. Melissa McMahon, The New Bergson, ed. John Mullarkey (Manchester: Manchester University Press, 1999), 53.

${ }^{37}$ Bergson, Creative Evolution, 34.

38 lbid., 58.

39 Ibid., 281.

40 Henri Bergson, Le parallélisme psycho-physique et la métaphysique positive," Mélanges (Paris: Presses universitaires de France, 1972), 487 (my translation). 
${ }^{41}$ Ibid., 488 (my translation).

42 Bergson, Creative Evolution, 270.

${ }^{43}$ Deleuze, Bergsonism, 74.

${ }^{44}$ Hegel, Hegel's Logic, 257-58.

${ }^{45}$ Bergson, Creative Evolution, 19.

${ }^{46}$ Ibid., 268

${ }^{47}$ Ibid., 271.

${ }^{48}$ Ibid., 269.

${ }^{49}$ Deleuze, Bergsonism, 91.

${ }^{50}$ Vladimir Jankélévitch, Henri Bergson (Paris: PUF, 1959), 174 ; Henri Bergson, trans. Nils F. Schott (Durham : Duke University Press, 2015), 144.

${ }^{51}$ Arnaud François, "Life and Will in Nietzsche and Bergson," SubStance 36.3 (2007), 101.

52 Pierre Montebello, "Nietzsche et Bergson: deux philosophes de la vie," Magazine littéraire 386 (2000): 53 (my translation).

${ }^{53}$ Friedrich Nietzsche, The Will to Power, trans. Walter Kaufmann and R. J. Hollingdale (New York: Vintage Books, 1968), 550.

${ }^{54}$ Bergson, Creative Evolution, 245

${ }^{55}$ Nietzsche, Beyond Good and Evil, trans. Judith Norman (New York: Cambridge University Press, 2002), 36.

${ }^{56}$ Nietzsche, The Will to Power, 368.

${ }^{57}$ Bergson, Creative Evolution, 249.

${ }^{58}$ Nietzsche, The Will to Power, 269.

59 Ibid., 281.

60 Ibid., 283

${ }^{61}$ Ibid., 550.

62 Ibid., 549.

${ }^{63}$ Bergson, Creative Evolution, 289. 